\title{
Não entre à esquerda, 1964
}

\author{
Stela Politano ${ }^{1}$
}

DOI 10.20396/eha.vil4.3418

Neste ensaio pretende-se detalhar o percurso da pintura "Não entre à esquerda" (1964) de Maurício Nogueira Lima (Recife, 1930 - Campinas, 1999) (figura 01) entre a elaboração, a exposição, o silenciamento e sua recente aparição na exposição "Os anos em que vivemos em perigo", do $\mathrm{Mu}$ seu de Arte Moderna de São Paulo². A relevância desta obra e o motivo de nos determos sobre ela se dá pelo contexto de sua criação e pela atualização política que ela propõe. Tadeu Chiarelli recentemente apontou que a pintura, em seu tempo, estava embebida pelo debate político e ideológico do país e colocava em xeque o ideário concretista, dentro de um processo de semantização nomeado por Augusto de Campos como Popcreto. "Para chocar" é a frase que a reportagem do jornal Folha da Tarde, de Porto Alegre (RS), do dia 14 de abril de $1965^{4}$, apresentou aos seus leitores a tela que fazia parte da exposição "Cinco arquitetos de vanguarda", evento de grande repercussão em solo gaúcho que ocorreria ao longo do mês de maio daquele ano. Hoje, "Não entre à esquerda" reativa a tradição cartazista da qual Maurício foi um ativo a partir da década de 1950 e escancara a nossa realidade atual.

Artista multimodal é como Walter Zanini definiu Nogueira Lima no II volume do seu manual História Ceral da Arte no Brasil (1983)5. Nascido em Pernambuco em 1930 mas radicado em São Paulo desde os dois anos de idade, durante a década de 1950 Maurício frequentou os cursos do IAC-Masp e desde do início de sua trajetória profissional ligou-se ao grupo Ruptura. Foi um artista de princípios dogmáticos e constantes instaurativas, principalmente nas animações óticas do espaço, na seriação das construções e na busca por retículas coloridas. Como designer gráfico, atuou na comunicação visual de revistas, cartazes, propagandas e logomarcas, marcando o início do design moderno brasileiro junto com Alexandre Wollner e Aloísio Magalhães. Arquiteto formado pela Faculdade Mackenzie, Maurício projetou residências, edifícios, escolas públicas e teve uma atuação

\footnotetext{
1 Instituto de Filosofia e Ciências Humanas - Universidade Estadual de Campinas (IFCH/Unicamp), Doutoranda em História da Arte. Bolsista CNPq.

2 Exposição "Os anos em que vivemos em perigo", curadoria de Marcos Moraes, Museu de Arte de São Paulo - MAM/SP, entre 30 de abril a 28 de julho de 2019.

3 CHIARELLI, T. 2019

4 AUTOR DESCONHECIDO, 14 de abril de 1965.

5 ZANINI, W. org. História geral da arte no Brasil. Apresentação de Walther Moreira Salles. São Paulo: Instituto Walther Moreira Salles, Fundação Djalma Guimarães, 1983: p.665-666.
} 
marcante na elaboração dos estandes comerciais e identidade visual das grandes feiras industriais de São Paulo, como a Feira Nacional da Indústria Têxtil (Fenit), Salão da Criança, Utilidades Domésticas (UD) e Salão do Automóvel. Ganhador de prêmios institucionais do Salão Paulista de Arte Moderna (SPAM) e da Bienal de Arte de São Paulo e personagem ativo no cenário artístico nacional, Nogueira Lima já gozava de certa reputação e prestígio desde o final dos anos 1950.

Entre 1964 e 1970, Maurício interrompeu a produção concreta por falta de equilíbrio emocional diante dos eventos sócio-políticos do país e por iniciar um movimento, compartilhado com Waldemar Cordeiro e com poetas concretos, de adesão à nova figuração. Sócio-fundador da Associação de Artes Visuais Novas Tendências em 1963 e participante da mostra coletiva inaugural da Galeria NT em dezembro do mesmo ano, Maurício executa suas retículas à óleo (figura 02) permitindo-se um gesto espontâneo em abandono a feitura rigorosa do projeto concreto da década de 1950. Após o golpe de 1964, Maurício começou a produzir colagens com imagens publicadas em jornais e revistas, numa iconografia baseada na fotografia em alto-contraste com repertório extraído dos meios de comunicação de massa. Essas obras foram expostas nos salões do Instituto de Arquitetos do Brasil (IAB/SP), junto com os primeiros popcretos de Waldemar Cordeiro, em junho de 1964.

É neste cenário que MNL realizou "Não entre à esquerda”. O aspecto gráfico da sinalização de trânsito, os comandos curtos, mas efetivos, somados à nomes de bairros, resultam numa imagem ambígua que alude à situação política do país pós-golpe militar. A articulação em “Não entre à esquerda" ocorre na pincelada, a partir da captura de um cruzamento paulistano: a placa de sinalização é o que chama atenção em primeiro lugar, junto com o "Não", semelhante à tipologia de um grito nos quadrinhos. $\mathrm{O}$ artista alerta. Escreve o título da obra no tecido da tela. As frases marcam o fundo branco: "Não entre à esquerda", "Conserve-se à direita" e "Entre pelo cano". O tom é de ordem, de perigo e, ao mesmo tempo, de provocação. A geometricidade do arranjo das setas orientadas conduzem caminhos e olhares: a exortação de manter-se à direita contrasta com a representação da esquerda da placa, relacionada à sinalização de regiões de São Paulo: à esquerda, Liberdade, Paraíso e Bela Vista, bairros de classe média e com nomes deleitáveis; à direita, Consolação, Casa Verde e Carandiru, zona norte, endereços da Casa de Detenção e do Campo de Marte e das classes baixas, locais de graves violações de direitos humanos durante a ditadura.

Há uma outra parte empírica na obra: signos plásticos dialogam com um elemento do cotidiano, deslocado do seu contexto e origem: dois mostradores de óleo e gasolina (figuras 03 e 04), respectivamente, oriundos de um carro da marca Renault Cordini (de fabricação brasileira, parceira com a Willys Overland do Brasil, empresa para qual Nogueira Lima prestava serviços de 


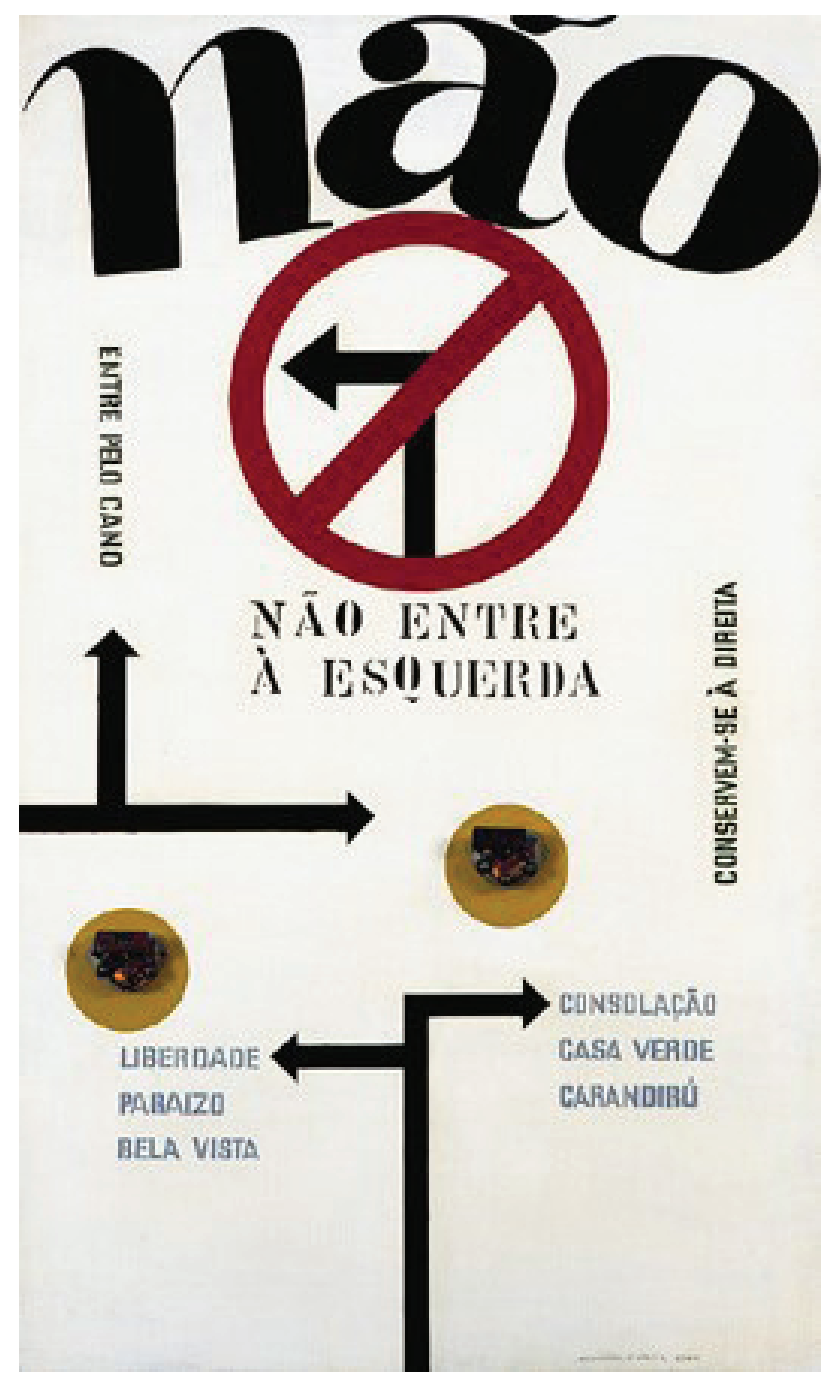

[Figura 01] Maurício Nogueira Lima (Recife, 1930 Campinas, 1999), Não entre à esquerda, 1964.

Metal e esmalte sintético sobre aglomerado, $99,2 \times 59,6 \mathrm{~cm}$. Acervo do Museu de Arte Moderna de São Paulo - MAM SP

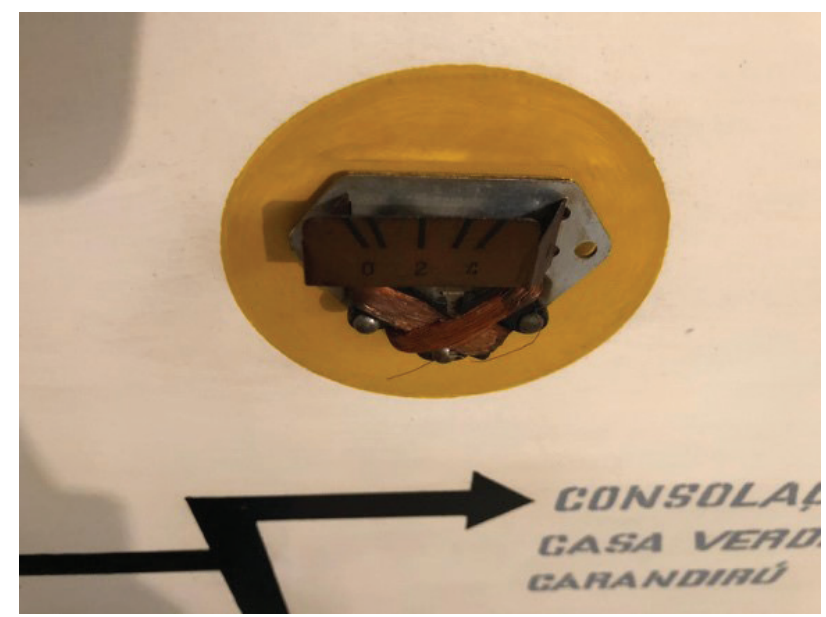

[Figuras 03 e 04] detalhes "Não entre à esquerda", 1964

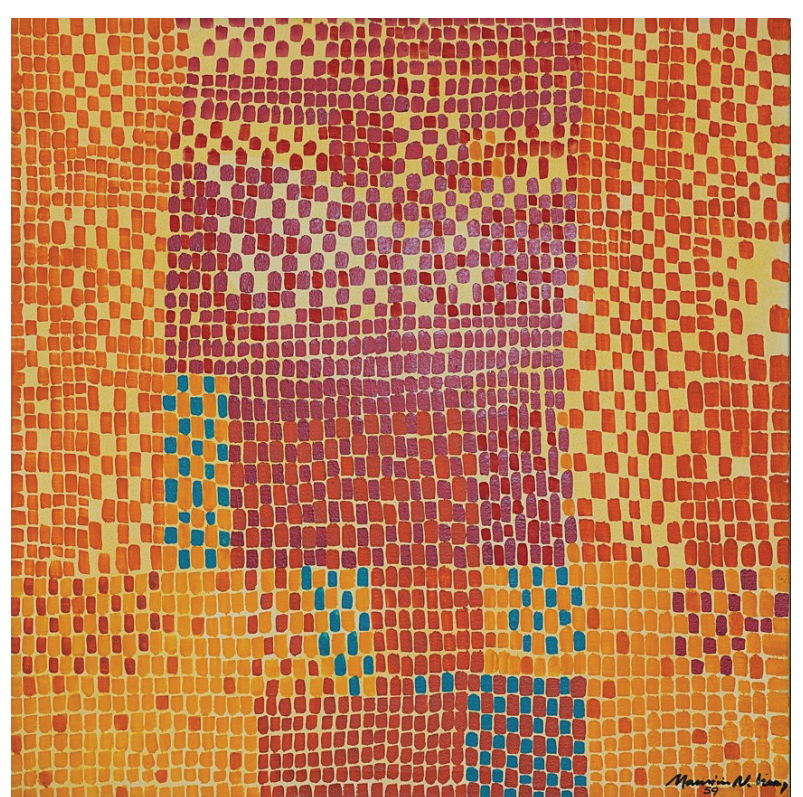

[Figura 02] Maurício Nogueira Lima (Recife, 1930 Campinas, 1999), Retícula, 1959.

Óleo e acrílica sobre tela, $61 \times 61$ cm. Acervo Selma Sevá.

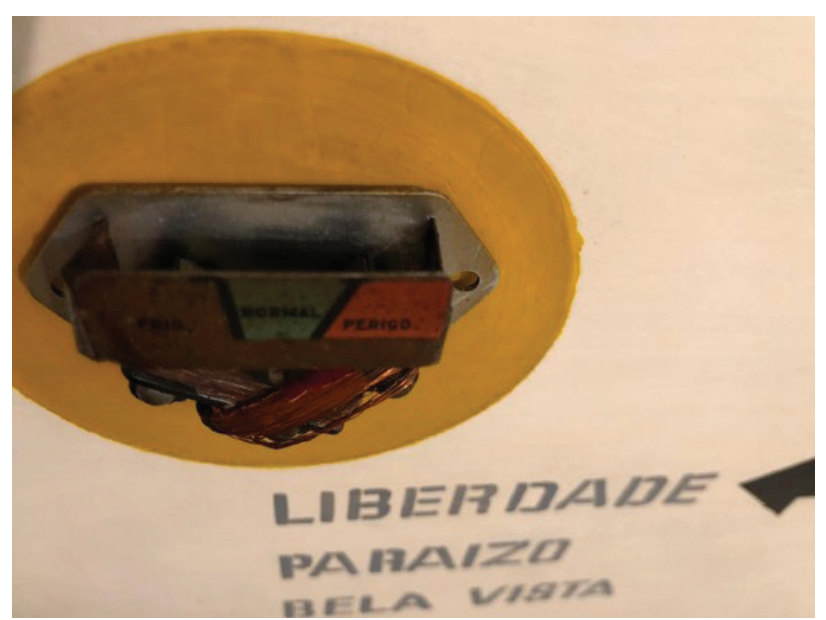


comunicação visual). Os objetos estão dispostos dentro de dois círculos amarelos, remetendo a ideia de faróis de carro ou de trânsito. O amarelo ilumina o caminho e também nos mantém alerta no cruzamento. "Não entre à esquerda" é empírico. As placas dos bairros são rememorações de placas reais, que existiam no cruzamento da Avenida Brigadeiro Luís Antônio com a Avenida Paulista e eram vistas pelos transeuntes que por ali passavam, oriundos da região da Vila Mariana, lugar de trabalho de muitos prestadores de serviços, domésticas e estudantes. Os mostradores de fluidos, posicionados dentro de dois círculos amarelos permitem movimento à pintura, um jogo de ilusão cinética que Maurício utilizava desde os tempos dos Objetos Rítmicos e das Retículas. Os faróis também poderiam ser os do carro da polícia, os vigias da ordem, ampliando a dialética repressãoliberdade, caminhar-parar, prosseguir-retornar.

A primeira aparição pública da obra "Não entre à esquerda" foi em outubro de 1964 no salão de exposições do IAB/SP (onde Maurício era sócio e ativo participante), junto com a sua série "Palavras", letras pichadas na tela, como muros de paisagem informação. As pinturas-poemas aproximavam-se do jogo concreto da tríade uspiana (Haroldo e Augusto de Campos e Décio Pignatari), incorporando o conceito joyciano de que palavra forma outra palavra e assim por diante.

O crítico José Ceraldo Vieira elogiou o fato de que um grupo de arquitetos expôs, simultaneamente, uma diversidade de ideias e propostas plásticas sem a necessidade de criar uma narrativa ou um ideário único. Outro elogio foi o fato de que a exposição não estava inserida em nenhuma instituição museológica ou na Bienal. A exposição localizada na rua Bento Freitas trazia nomes de peso como Flávio de Carvalho, Rino Levi e Ubirajara Ribeiro, além de Maurício Nogueira Lima, com suas "manifestações ousadas cromáticas no tipo não do poema-objeto de Breton, mas talvez da paisagem-com-colagens, revolucionando o cartaz e o 'industrial design'"6.

Além da nova proposta plástica, Maurício cunhou o termo "coisicidades", que são os objetos banais do cotidiano que estruturam e compõe as telas a partir da grade concreta. $O$ termo aparece na mídia pela primeira vez com José Geraldo Vieira, em janeiro de $1965^{7}$, como parte do balanço crítico das atividades artísticas do ano anterior. O artigo intitulado "Vetores e quocientes" trata das duas principais linhas de produção artística que dominaram o ano de 1964: os vetores, nomeados por José Ceraldo, Nova Figuração e Novas Tendências. O quociente, "uma modalidade aliás bem brasileira", seria o popcreto de Waldemar Cordeiro, onde as coisicidades de Maurício dialogavam 
com a rotina da cidade, criando uma didascalia urbana.

Em março de 1965, o artista realizou uma individual na Galeria Mobilinea (rua Augusta, 875, São Paulo), onde apresentou os mesmos trabalhos do IAB além de novas proposições. Ivo Zanini, em artigo intitulado "Arquiteto vai mostrar (com pinturas) males da cidade grande" ${ }^{8}$ salientou, além do currículo de Nogueira Lima, o fato de que o arquiteto-artista apresentou obras repletas de coisas comuns, "pintadas ou coladas", sejam nomes de pessoas conhecidas, fotos de gente de primeira página de jornal, semáforos, letreiros, etc. O catálogo da exposição, feito pelo próprio artista, apresentou no lugar de um texto crítico, o poema autoral "a exposição" (figura 05). É com a utilização do recurso poético que ele exprimiu a urgência do momento do novo realismo, como um levante. $O$ gesto manual do artista, o anonimato urbano, a cidade e seus elementos, o estado geral das coisas são as coisicidades do próprio poema.

"Não entre à esquerda" continuou seu percurso. Da rua Augusta para o Museu de Arte do Estado do Rio Grande do Sul, em Porto Alegre. Em maio de 1965, o diretor Carlos Scarinci organizou a exposição "Cinco Arquitetos de Vanguarda" com o objetivo de levar para o sul do país o que ele definia como vanguarda paulista. Ressaltou, em texto de divulgação do evento publicado na reportagem "Os marinheiros de Colombo" , que a exposição não era uma mostra pop mas sim o resultado da liberdade plástica e das influências artísticas como o dadaísmo, surrealismo, concretismo paulista e pop art norte-americana. A produção, segundo Scarinci, era original, reflexo do espírito brasileiro, de tom ousado, nacional e corajoso. $O$ aspecto que reunia o grupo era o fato de serem artistas figurativos que faziam crítica social através da pintura utilizando materiais do cotidiano. O caráter comum era a postura política e de crítica.

A inauguração gerou expectativa no público, alimentada pelas notícias da imprensa: os artistas Ubirajara Ribeiro, MNL, Flávio Império, Sérgio Ferro e Samuel Szpigel estariam presentes para debates, entrevistas para a televisão e discussão junto ao público. Apenas Ubirajara, MNL e Szpigel foram, de fato, na abertura da exposição, acompanhados pelo poeta Sérgio Claudio de Franceschi (convidado do Instituto Estadual do Livro) ${ }^{10}$.

O grupo denominado pela imprensa como "Folclore Urbano Paulista" gerou polêmicas, debate acirrado durante dois meses e muitas alfinetadas por todos os lados. Detalhe é que a exposição

\footnotetext{
8 ZANINI, I. "Arquiteto vai mostrar (com pinturas) males da cidade grande", Folha de São Paulo, São Paulo (SP), 13 de março de 1965.

9 SCARINCI, C. "Os marinheiros de Colombo", Correio do Povo, Porto Alegre (RS), 14 de maio de 1965. O texto foi publicado no catálogo da exposição publicado em junho de 1965.

10 Autor desconhecido, "Folclore Urbano Paulista apresentar-se-à no Sul", Folha da Tarde, Porto Alegre (RS), 14 de abril de 1965.
} 


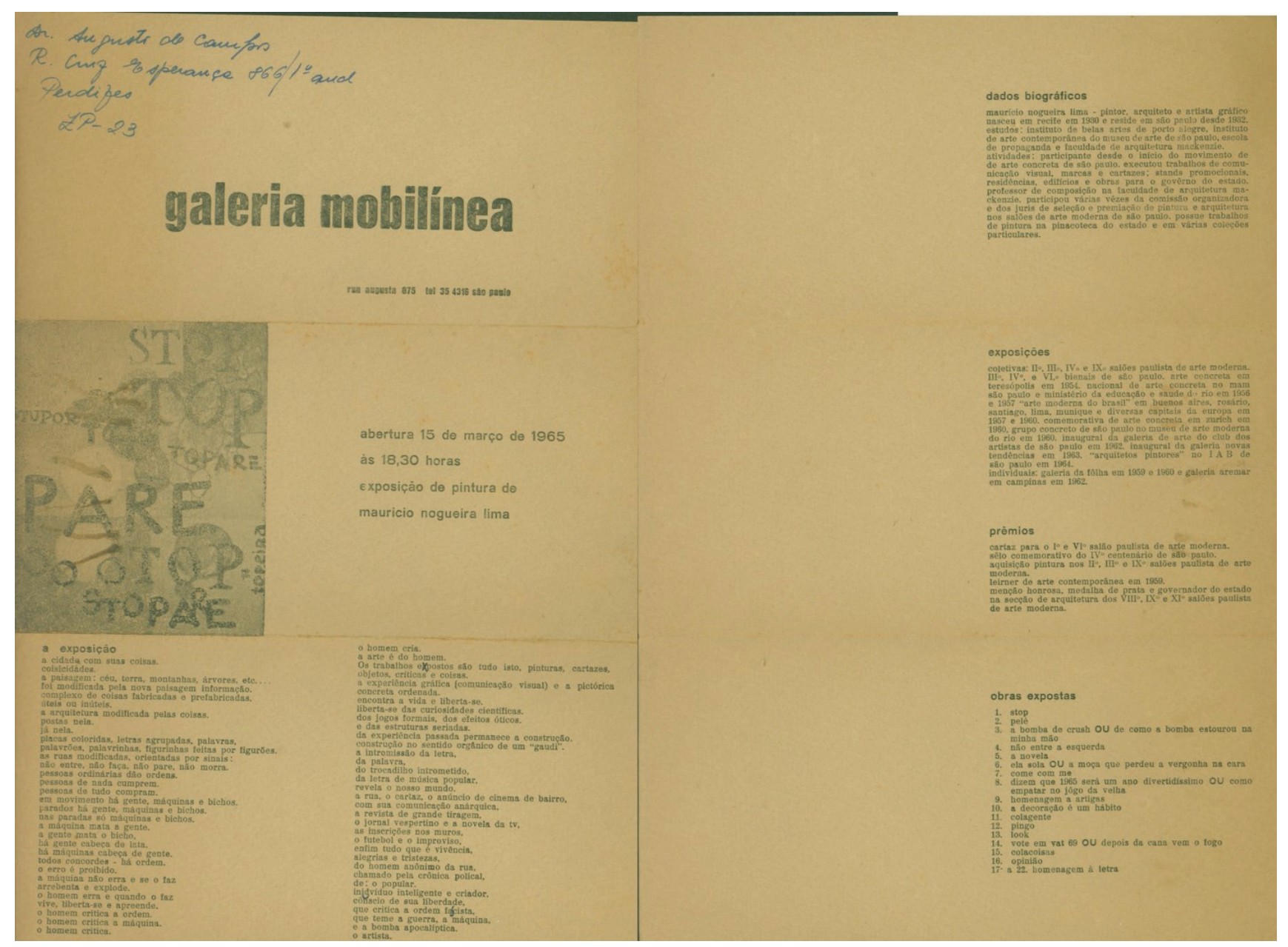

[Figura 05] poema "a exposição", de Maurício Nogueira Lima. Texto crítico do catálogo da sua individual de 1965, Galeria Mobilinea, São Paulo. 
durou duas semanas, mas foi o suficiente para agitar o circuito artístico da cidade e ser a exposição de maior público que o museu tinha tido até então. Superando até mesmo a retrospectiva de Di Cavalcanti no ano anterior. De um lado, Ubirajara Ribeiro, MNL, Carlos Scarinci, Francisco Stockinger e Miguel Alves Pereira, em defesa à exposição. Do outro, artistas locais liderados por Eloí Calage, jornalista do Correio do Povo responsável pela cobertura dos eventos sociais e artísticos de Porto Alegre e contrária aos artistas mais do que aos quadros.

Ubirajara Ribeiro se posiciona a partir de uma carta enviado ao jornalista Eloí Calage que a publica na íntegra no artigo "Duas Cartas - Duas oposições", de 11 de junho de $1965^{11}$. Ubirajara resume o ambiente proposto pelos artistas: eles queriam movimentar o ambiente plástico da cidade, mesmo se apropriando de meios agressivos, sejam visuais ou verbais. Palavras de Ubirajara:

[nós] achamos [os meios] próprios e legítimos, principalmente levando em conta toda uma técnica promocional característica de nossa era industrial, era já em fase de superação, pois o negócio agora é foguete, átomo, lua, mescalina, felicidade artificial. ${ }^{12}$

Ubirajara apresentou em Porto Alegre treze obras. Maurício dez, Szpigel nove, Império oito e Sérgio Ferro cinco, totalizando quarenta e cinco telas, levadas de São Paulo à Porto Alegre. Algumas obras de Maurício não voltaram e ainda não se sabe a procedência. No entanto, "Não entre à esquerda" retornou ao circuito paulistano para a exposição Proposta 65, em dezembro. Nesse meio tempo, Maurício atuava como docente no Mackenzie e na FAAP, iniciava a série Beatles e apresentava três colagens na VIII Bienal de São Paulo (de setembro a novembro de 1965). Mário Schenberg ressaltou, em dezembro $1965^{13}$ em texto crítico sobre os arquitetos pintores, que Maurício após um início neo-realista fortemente marcado pela grade concretista começou a inserir figuras pintadas em suas superfícies, preferindo a inclusão através das tintas das formas narrativas. A eliminação da colagem traz mais organicidade e simplicidade à composição, de requintada sensibilidade cromática. A vivência no campo da publicidade e o reavivamento da narrativa dos gibis possibilitava MNL trabalhar um macronaturalismo de efeitos monumentalizantes a partir de uma crítica social irônica. A figura é pensada como design e é só mensagem.

A partir de 1966 "Não entre à esquerda" permaneceu na casa/ateliê do artista para retornar ao público apenas em 1984, na primeira e única retrospectiva de Maurício Nogueira Lima no Centro

\footnotetext{
1 CALAGE, E. "Duas Cartas - Duas oposições", Correio do Povo, Porto Alegre (RS), 11 de junho de 1965.

2 RIBEIRO, U. in CALACE, E. Ibdem.

3 SCHEMNBERG, M. "Cinco arquitetos pintores", Revista Acrópole, São Paulo, dezembro de 1965.
} 
Cultural São Paulo (CCSP) ${ }^{14}$. A obra é adquirida pelo MAM/SP entre 1996-2000 na gestão de Tadeu Chiarelli. Foi emprestada para a exposição "Fraturas da Forma", de 2008, no Centro Cultural Maria Antonia (São Paulo) e em 2019 foi reapresentada no MAM/SP na exposição "Os anos em que vivemos em perigo", de curadoria de Marcos Moraes.

Em entrevista à Cecília Pimenta em 19835, Maurício Nogueira Lima relatou que "até 64 as coisas corriam bem" na sua vida artística e profissional. Foi devido a um telegrama de apoio a Cuba, frente a ameaça de invasão dos Estados Unidos, documento assinado pelo artista e por mais uma centena de pessoas, que Maurício sofreu um inquérito policial militar. Segundo o artista, foi a partir desse momento que ele passa "a realizar trabalhos dentro de uma linguagem que não fazia parte do percurso projeto" mas que eram a única possibilidade de caminho. O marco inicial desse inesperado caminho foi "um quadro eminentemente gráfico", quase como um cartaz ou "um poema-objeto": "Não entre à esquerda". O concreto Maurício afirmou que o quadro era "mal realizado a nível de acabamento e de material" pois constituiria uma arte povera.

No fundo, o que eu queria era falar da miséria da forma mais contundente: com recursos miseráveis. Na verdade, esse é um trabalho nada metafórico, a mensagem é passada de forma essencialmente explícita. ${ }^{16}$

O que se encontrou, até o momento, relacionado diretamente com a ditadura foi um dossiê de $n^{\circ}$ 391602/ASP/SNI/73, datado de 14 de dezembro de 1973, disponível para consulta no Sistema de Informações do Arquivo Nacional (SIAN), onde consta que MNL não era um militante comunista, não participou de nenhum congresso em Havana (teria sido o arquiteto Maurício Nogueira Batista, secretário do $I A B$ ), possuía um "sósia" que assinava como M.Nogueira Lima (só que era um artista/arquiteto carioca de nome Milton) e era um "elemento idôneo, capaz e bom profissional, sendo a sua ideologia-política-liberal"17. Encontram-se mais cinco documentos relacionados à Nogueira Lima no arquivo ASP/SNI, datados entre 1976 a 1986 e relacionados com greves, arrecadação de fundos para o Partido Comunista Brasileiro, memoriais para desaparecidos e centros de cultura. Em todos, sua participação não é de liderança mas sim de apoiador. Existe ainda um dossiê do DOPS datado de 1978 e localizado no Arquivo do Estado que ainda não tivemos acesso e que será fruto de

\footnotetext{
14 Exposição "Visão Construtivista de Maurício Nogueira Lima", Centro Cultural São Paulo, 1984.

15 PIMENTA, C. "Ideário Concretista", in artes:, editora artes:Itda, São Paulo, edição n.57 dezembro de $1983 /$ janeiro de 1984.

16 LIMA, M.N. in PIMENTA, C. Ibdem, p.51.

17 Arquivo "BR DFANBSB V8.MIC, GNC.EEE.81005907 - mauricio nogueira lima. - Dossiê" Link: http://sian.an.gov.br/sianex/Consulta/Pesquisa_Livre_Painel_Resultado.asp?v_CodReferencia_id=1901585\&v_aba=1
} 
pesquisa futura.

Maurício nunca se declarou um militante. O que se percebe, em suas falas e atividade profissional, é que a produção política era um único caminho encontrado entre 1964 e 1966. O contato com os universitários do Mackenzie e da Faculdade Fundação Álvares Penteado, com as duas filhas adolescentes e com o universo da propaganda fez abriu novas perspectivas como artista ao olhar os ídolos da música e do futebol. Sem abandonar a perspectiva construtiva, Maurício direciona o olhar para a Pop Arte e, ainda dentro da estrutura de poema-quadro, aborda os símbolos como Pelé, Roberto Carlos, Beatles.

Em 1973, após as polêmicas da Nova Objetividade e uma institucionalização do ideário concreto, Maurício retorna ao laboratório de pesquisa e à abstração, explorando a geometria e (principalmente) a cor. "Não mais a 'cor geográfica' da década de 50, mas a cor programada, surgindo como elemento efetivamente atuante no discurso plástico"18. Nesse momento, era professor na Faculdade Brás Cubas de Santos e pleiteava um cargo de professor na FAU-USP (que conseguiu em 1974).

Maurício Nogueira Lima era um comunicador mais do que um ativista. Com "Não entre à esquerda" conseguiu reunir o cartaz, a manchete do jornal, a problemática concreta, o signo, a figuração e o cotidiano/coisas em um suporte. A obra carrega um posicionamento político declarado e produz uma ressonância crítica que, infelizmente, perpetua até hoje.

18 LIMA, M.N. in PIMENTA, C. "Ideário Concretista", in artes:, editora artes:Itda, São Paulo, edição n.57 dezembro de 1983/janeiro de 1984, p.52. 


\section{Referências bibliográficas}

AUTOR DESCONHECIDO. "Folclore Urbano Paulista apresentar-se-à no Sul", Folha da Tarde, Porto Alegre/RS, 14 de abril de 1965 .

CALAGE, Eloí. "No Rio Grande ainda se resiste à Arte Moderna", Jornal Correio do Povo, 14 maio 1965, Porto Alegre/RS.

CHIARELLI, Tadeu. "Concreto, neoconcreto: a semantização continua", Revista ARTE!Brasileiros, 2 de outubro de 2019, São Paulo/SP. Matéria digital, acessado em 09 de dezembro de 2019. Link: https://artebrasileiros.com.br/opiniao/conversa-de-barr/concreto-neoconcreto-a-semantizacao-continua/

PIMENTA, Cecília. "Ideário Concretista", artes:, editora artes:Itda, São Paulo, edição n.57 dezembro de 1983/janeiro de 1984

SCARINCI, Carlos. Cinco Arquitetos de Vanguarda. Catálogo da Exposição, maio de 1965, Museu de Arte de Porto Alegre/RS

SCHENBERG, Mário. "Cinco arquitetos pintores", Revista Acrópole, São Paulo, dezembro de 1965.

VIEIRA, José Geraldo. "Exposição de arquitetos", Jornal Folha de São Paulo, 20 de outubro de 1964, São Paulo/SP.

ZANINI, Ivo. "Arquiteto vai mostrar (com pinturas) males da cidade grande", Jornal O Estado de São Paulo, 13 de março de 1965, São Paulo/SP.

ZANINI, Walter, org. História geral da arte no Brasil. Apresentação de Walther Moreira Salles. São Paulo: Instituto Walther Moreira Salles, Fundação Djalma Guimarães, 1983. 